The BDJ News section accepts items that include general news, latest research and diary events that interest our readers. Press releases or articles may be edited, and should include a colour photograph if possible. Please direct your correspondence to the News Editor, Arveen Bajaj at the BDJ, The Macmillan Building, 4 Crinan Street, London N19XW or by email to bdj@bda.org

\section{On the alert}

Orthodontist Keith Isaacson has become the first dental member to join the committee of Health Watch. The organisation is committed to ensuring that treatment is clinically effective, and to counteracting the exaggerated claims of miracle cures by untried medicines and techniques, that can reach the popular press and television.

Dr Isaacson's particular concern is the number of patients that he sees where unsubstantiated claims are made for the benefits of orthodontic treatment. These can include in some cases, improving the patient's spinal curvature and posture. Dr Isaacson (right) is pictured with Nick Ross, President of Health Watch and presenter of BBC television programme Crimewatch UK. For more information visit www. healthwatch-uk.org.

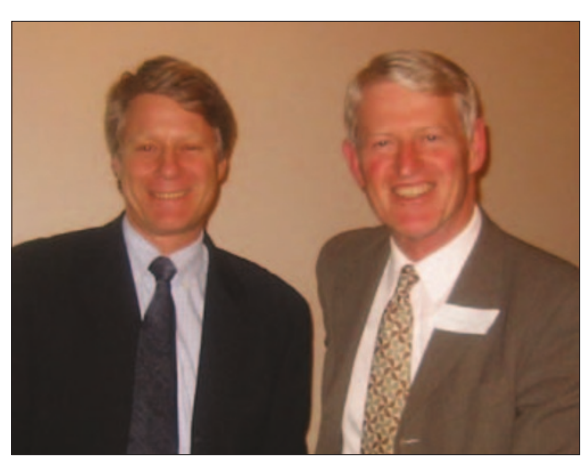

\section{Sheffield orthodontist wins} award

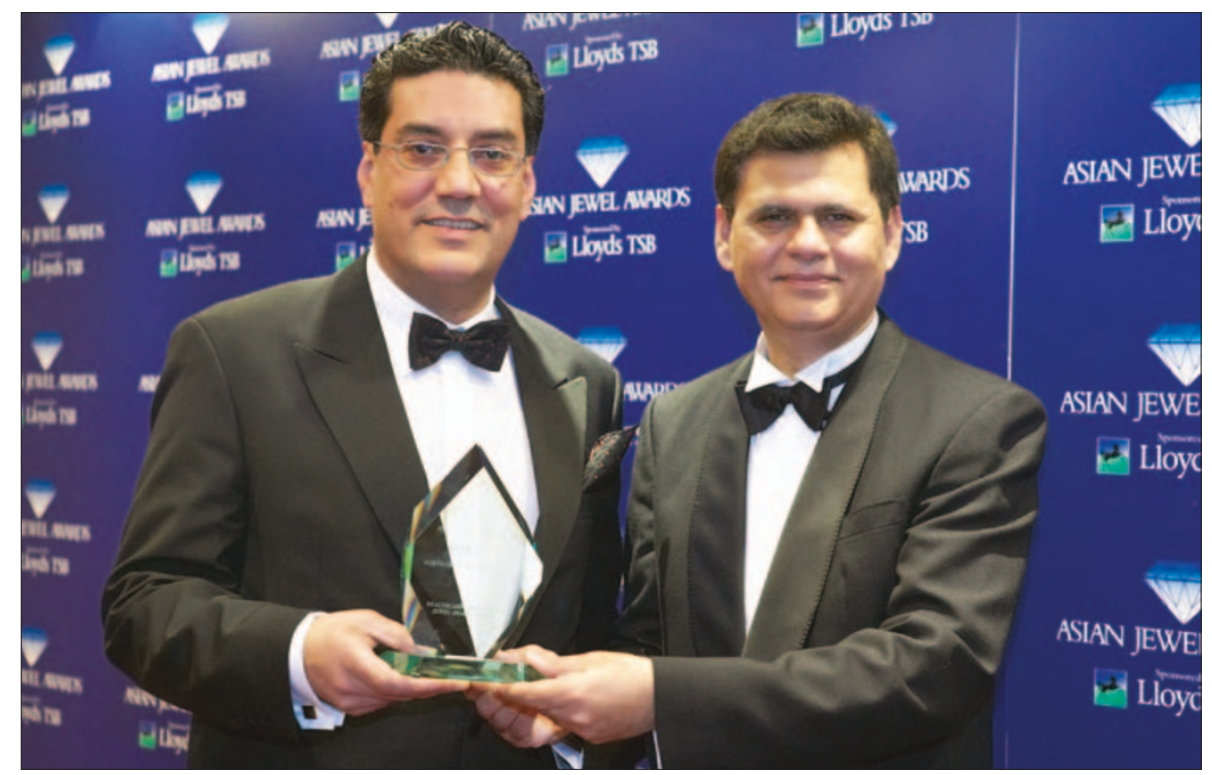

A Sheffield-based orthodontist has won the Healthcare and Education Award at this year's Lloyds TSB Northern Asian Jewel Awards in recognition of his advances in dental care. Dr Sonil Kalia was presented with his award at the Lloyds TSB Northern Asian Jewel Awards, in Manchester. The Awards recognise inspirational high achievers from the region's Asian communities. Dr Kalia, who gained his dental degrees in Sheffield and London, has pioneered the use of cutting edge dental technology in his company Orthoscene. Working across the UK and Europe, he specialises in implantology to correct dental and jaw abnormalities. As well as running practices in the UK and Germany, Dr Kalia also teaches dentistry in Denmark on a regular basis. The Northern Asian Jewel Awards, now in their third year, form part of a nationwide search for Asian high flyers in the UK today. Other categories included Business and Commerce, Media, Arts and Sports and Lifetime Achievement. Pictured above: Dr Kalia (left) receiving the Healthcare and Education Award from Dr Mohammed Iqbal.

\section{Recycle for Comic Relief}

Although Red Nose Day has come and gone, dentists can still raise money for Comic Relief this year by recycling old mobiles phones or inkjet printer cartridges.

Recycling company Eurosource has pledged to give cash to Comic Relief for every mobile and cartridge recycled through its new appeal. The eco-friendly fundraiser will help raise money for the charity, which is committed to helping end poverty and social injustice in the UK and the world's poorest countries.

Jamie Rae, chief executive of Eurosource, said: "Red Nose Day encourages people to do something out-of-the-ordinary to raise funds. Sadly, for a lot of people in Britain, recycling is outof-the-ordinary, so we want to encourage more people to be environmentally friendly and help this great charity at the same time."
Different mobiles and cartridges are worth different sums of money depending on various factors like model and age. Epson cartridges cannot be accepted.

If you want to help the Red Nose Day Recycling Appeal, put your old mobile or inkjet cartridge in a secure envelope and post it to Comic Relief Recycling Appeal, Freepost NAT1990, Falkirk, FK2 9BR. Mobiles and cartridges must be posted by April 15 to allow time for the donations to be processed and the proceeds to be sent to Comic Relief.

For further information visit www.recyclingappeal.com/rednoseday or call 08712505050 . 


\section{New board of advisors at the $B D J$}

The $B D J$ has appointed a new board of advisers. The new advisers are Dr Paul Batchelor, Professor Andrew Eder, Professor John Gibson, Professor Wayne Richards, Professor Aubrey Sheiham, Professor Jonathan Shepherd, Dr Philip Sloan, Professor Paul Speight, Professor Damian Walmsley, Professor Richard Welbury and Professor Nairn Wilson.

The Scientific Advisor to the BDJ is Professor John Murray CBE, and to the BDA is Professor Elizabeth Kay. An advisor on statistics is to be announced.

\section{European dental school smoking policies lagging behind US}

A ten-year follow up study to investigate the policies and practices of European dental schools in relation to smoking found that while improvements were seen in the practices of most schools, comparison with recent US data suggested that European schools lagged behind.

Professor Bernard McCartan, Professor of Oral Medicine and Professor Diarmuid Shanley, Dean at the Faculty of Health Sciences, both of Trinity College Dublin, surveyed 201 European dental schools in 2003 and compared the results with a previous study from 1993. They found that 80 schools (59\%) had written tobacco policies, 132 (92\%) banned smoking in clinical areas, 127 (89\%) in non-clinical areas and 122 $(85 \%)$ in public access areas.

One hundred and seven (76\%) expected students to take tobacco histories from all patients, while $79(69 \%)$ and $100(70 \%)$ respectively taught students anti-smoking advice and expected them to give such advice.

The number of schools teaching the role of tobacco in oral cancer aetiology was 133 (93\%), 135 (94\%) in periodontal disease and 127 (91\%) in osseointegrated implant failure. There was considerable regional variation between northern, southern and eastern Europe.

Direct comparison of the responses of the 78 schools that replied in both 1993 and 2003 showed some improvements in most of their policies and practices. However, there was some deterioration in the practices of southern European schools.

Professor McCartan said, "Many European dental schools are failing to exploit the proven effectiveness of dentists helping patients to quit smoking. It is also worrying that there are still some schools that don't teach the links between smoking and oral diseases."

The full study will be published in next issue of the $B D J$.

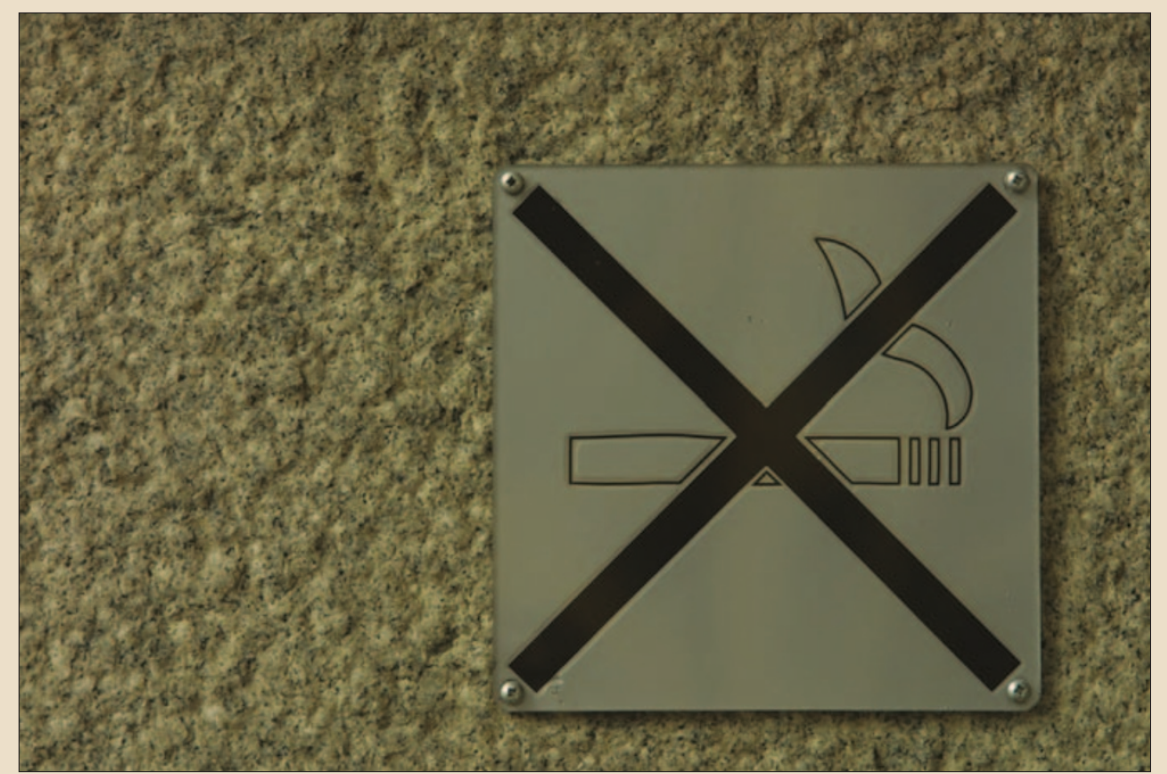




\section{DIARY}

April 2005

Academy of Laser Dentistry Source 2005:

Lasers in Dentistry

Date: 6-9.04.05

Venue: New Orleans Marriott Hotel, New

Orleans, Louisiana, USA

Tel: 1-877-527-3776

Email: memberservices@laserdentistry.org

www.source2005.org

\section{Dental Sedation Teachers' Group Annual}

Symposium 2005

Date: 26.04.05

Venue: The Royal College of Physicians and Surgeons, London

Tel: +44 (0) 1412216072

Fax: +44 (0) 1412211804

Email:n.d.robb@dental.gla.ac.uk

www.dstg.co.uk

Irish Dental Association Annual Scientific

Conference

Date: 14-16.04.05

Venue: Killarney, Ireland

Tel: 0035312830499

Email: info@irishdentalass.ie

IDS International Dental Show

Date: 12-16.04.05

Venue: Cologne

Tel: +44 $01604-621014$

Fax: +4408709909523

Email: tradefairs@yorks-travel.co.uk www.idfdentalconference.com

FGDP UK \& FDS Dentists with a Special Interest Date: 21.04 .05

Venue: The Royal College of Surgeons of England, London

Tel: +44 (0) 2078696758 / 6768

Email: fgdp@rcseng.ac.uk

www.rcseng.ac.uk/fgdp

\section{May 2005}

The Association of Dental Implantology (ADI) 2005 International Congress

Date: 12-14.05.05

Venue: Edinburgh International Congress Centre

Tel: +44 (0) 2084875555

Fax: +44 (0) 2084875566

Email: adi.uk@btinternet.com

www.adi.org.uk

The BDA 2005 British Dental Conference and Exhibition

Date: 19-21.05.05

Venue: Scottish Exhibition and Conference Centre (SECC), Glasgow

Tel: 08701666625

Email: events@bda.org

www.bda-events.org

\section{New certificate launched}

A new Certificate in Dental Radiography that allows dental nurses to take X-rays in compliance with current legislation has been launched. The qualification is awarded by the National Examining Board for Dental Nurses (NEBDN) and candidates for the qualification must be trained in both the theory and practice of taking radiographs. Assessment is by a multiple-choice examination and completion of a Record of Experience in taking a range of common radiographs.

The BDA is currently developing a web-based course that demonstrates the practice and teaches the theory required for the Certificate. It will be launched at the 2005 British Dental Conference and Exhibition in Glasgow in May.

The certificate was developed with the help of the College of Radiographers, the British Dental Association and the British Society of Dental and Maxillofacial Radiology and supported by the Dental Nurse Standards and Training Advisory Board of the General Dental Council. The first candidates will be able to take the written examination in June 2005 with subsequent assessments taking place twice a year in centres around the UK.

Further details about the Certificate in Dental Radiography are available from Jennifer Lavery of the National Examining Board for Dental Nurses at 110 London Street, Fleetwood, Lancashire FY7 6EU or on 01253778417 and at www.bda.org.

\section{Research undertaken}

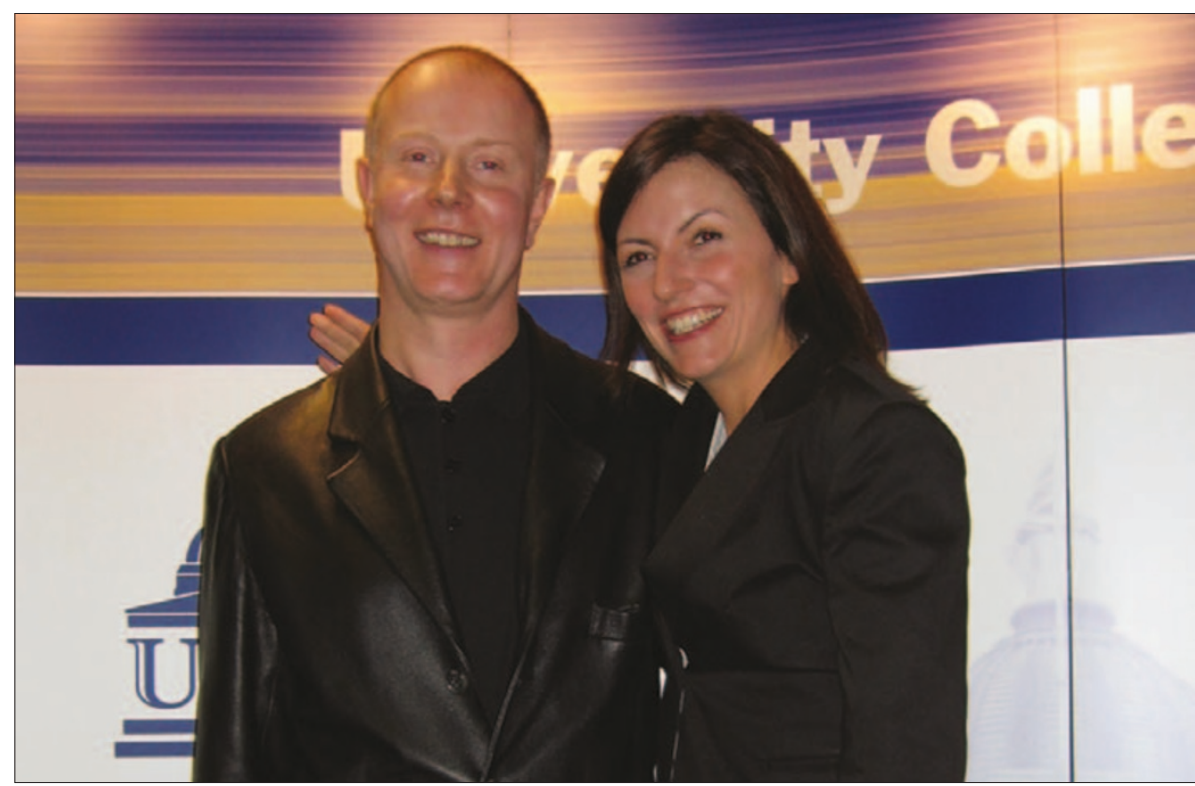

Dr Richard Watt (University College London) and a team of researchers are currently undertaking a randomised controlled trial funded by the Food Standards Agency to evaluate the impact of peer support on a range of infant feeding outcomes including sugars consumption. At a recent UCL event TV presenter Davina McCall (pictured with Richard Watt) thanked the volunteers involved in the intervention for all their hard work.

\section{New fund raising events}

Two UK charities are looking for dynamic, adventurous individuals who want a demanding but rewarding challenge. The British Lung Foundation (BLF) and Shelter, the housing and homelessness charity, are both running challenging fund raising events.

The BLF want people to join in the Everest Base Camp Trek from 12-30 November 2005 while Shelter is looking for people who want to scale the three highest peaks in England, Wales and Scotland as part of its annual Three Peaks Challenge in May (20-22nd).

For more information contact BLF on 02076885581 or email events@blf-uk.org and Shelter on 0845458 4590, www.shelter.org.uk/threepeaks, or email send-for-it@shelter.org.uk. 


\section{Emergency treatment in Wales}

A full-time dentist has been employed by Pembrokeshire Local Health Board - the first in Wales - to provide emergency dental treatment to those people who do not have an NHS dentist.

Dr Devendra Rajcoomar has been recruited from the West Indies and began work in Milford Haven in March. He will treat people in Pembrokeshire who currently have no access to an NHS dentist and are in pain. He will see them on a See and Treat basis although patients will not be registered, they will not only be treated for their immediate pain, but will be offered further appointments to complete any necessary treatment.

Dr Rajcoomar has worked for many years in community dentistry focusing on the needs of children and emergency care for adults. He has been a clinical instructor at a dental school in the West Indies and is also a member of the International Congress of Oral Implantologists.

The Local Health Board has forged a partnership with an existing NHS practice. Dr Rajcoomar will work full-time from Haven Dental Practice in Great North Road. Patients will be seen on an appointment-only basis and must ring the practice in advance. The Local Health Board will also be contacting those people currently on its database to offer a dental assessment with Dr Rajcoomar.

\section{Sports drinks trial finds high levels of tooth erosion}

Scientists at the University of Birmingham are warning athletes that continued use of high performance sports drinks can lead to alarming levels of tooth erosion. The University's Schools of Sport and Exercise Sciences, and Dentistry joined forces on a study into the erosive effects of sports drinks.

In a trial recreating intensive exercise conditions, it was found that some sports drinks can cause up to 30 times more enamel loss than water. However, the study points to low-erosion technology that could mean sports drinks are as harmless to teeth as water.

Previous trials of sports drinks have shown that they are beneficial to athletes by improving hydration and boosting energy. Elite athletes consume between 5 and 10 litres of performance drinks a day during training. A higher acidity level in sports drinks is included for taste and to increase the shelf life of the product. However, sports people are at particularly high risk of tooth erosion, as they have dry mouths so do not produce enough saliva to regulate the acidity of sports drinks.

The study involved a group of active participants who wore mouth protectors to protect their own teeth, with enamel samples mounted into the gum shield. The participants then trialled two different types of sports drink and water. The athletes carried out 75 minutes of exercise to recreate accurate sports conditions and drank the same drink every day for three-week blocks. When studying the enamel samples, water did not cause erosion; a low-erosion prototype drink had a similar effect; yet a performance sports drink caused up to 30 times more erosion.

Dr Tony Smith, Head of Research at the University of Birmingham's School of Dentistry commented, "Tooth erosion can be a significant problem as when the enamel is dissolved the tooth becomes a lot more sensitive. Eventually the hard dentine and pulp can be exposed, leading to infection. This study has shown that whilst an existing sports drink was erosive, it has been possible to formulate this new sports drink with negligible erosive potential. It's also important to remember that similar erosive problems can occur when drinking fruit juices or fizzy drinks".

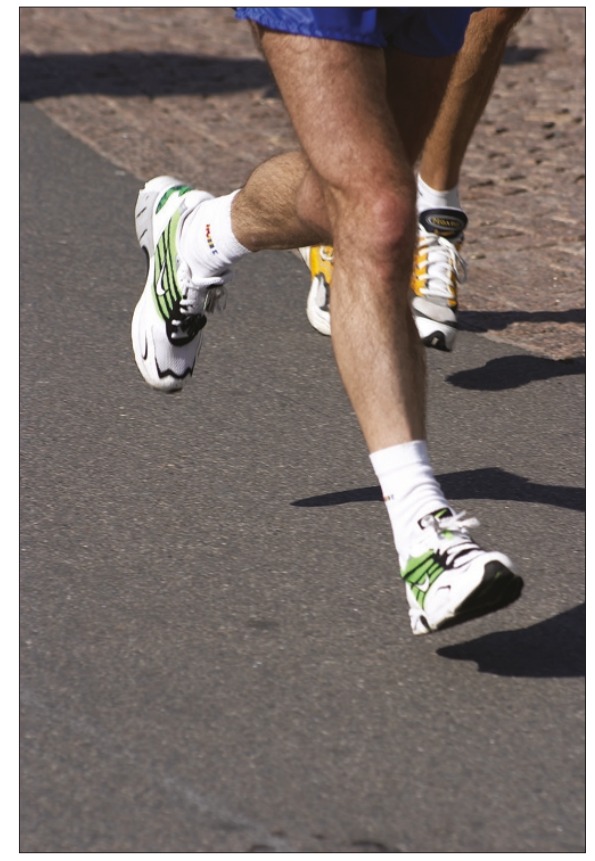

